\title{
Perfil epidemiológico das vítimas de intoxicação exógena em Porto Nacional (TO) no período de 2013 a 2017
}

As intoxicações são ações químicas que podem lesar o corpo, através da exposição a substâncias químicas do ambiente ou isoladas, como medicamentos, produto químicos, plantas, pesticidas, entre outros. Ela pode ser causada de forma acidental ou intencional, onde a tentativa de suicídio é a principal circunstância da forma intencional. Devido à intoxicação exógena poder levar a óbito, ela está inserida na lista das doenças de agravos de notificação compulsória. Seus dados podem ser encontrados por meio do DATASUS do SINAN. Desse modo, buscou-se uma investigação no DATASUS do perfil epidemiológico das vítimas de intoxicação exógena em Porto Nacional (TO), para contribuir para o desenvolvimento de estratégias e ações preventivas, visto que não há artigos que evidenciem este perfil para o município. Identificou-se que a maior parte das vítimas são mulheres, de cor parda, entre 20 e 39 anos, que buscam a tentativa de suicídio principalmente por meio de medicamentos.

Palavras-chave: Toxicologia; Intoxicação exógena; Perfil epidemiológico; Porto Nacional.

\section{Epidemiological profile of exogenous poisoning victims in Porto Nacional (TO) from 2013 to 2017}

\begin{abstract}
Intoxications are chemical actions that can harm the body through exposure to environmental or isolated chemicals such as medicines, chemicals, plants, pesticides, among others. It can be caused accidentally or intentionally, where attempted suicide is the main circumstance of intentional form. Because exogenous poisoning can lead to death, it is included in the list of diseases of compulsory notification diseases. Your data can be found through SINAN DATASUS. Thus, we sought an investigation in DATASUS of the epidemiological profile of victims of exogenous poisoning in Porto Nacional (TO), to contribute to the development of strategies and preventive actions, since there are no articles that evidence this profile for the municipality. It was found that most victims are brown women, between 20 and 39 years old, who seek suicide attempts mainly through medication.
\end{abstract}

Keywords: Toxicology; Exogenous intoxication; Epidemiological profile; National port.

Topic: Análises Clínicas e Toxicológicas

Reviewed anonymously in the process of blind peer.
Received: $11 / 03 / 2019$

Approved: 14/05/2019
Tarcis Roberto Almeida Guimarães

Instituto Tocantinense Presidente Antônio Carlos, Brasil

http://lattes.cnpq.br/2213203602252143

tarcis.roberto@gmail.com

\section{Renata Karoliny Batista Lopes}

Instituto Tocantinense Presidente Antônio Carlos, Brasil

http://lattes.cnpq.br/9546410701627275

renatalopesrr@hotmail.com

Guilherme Vaz Burns

Centro Universitário AGES, Brasil

http://lattes.cnpq.br/9203946709315503

guilhermevazburns@hotmail.com
Referencing this:

GUIMARÃES, T. R. A.; LOPES, R. K. B.; BURNS G. V.. Perfil epidemiológico das vítimas de intoxicação exógena em Porto Nacional (TO) no período de 2013 a 2017. Scire Salutis, v.9, n.2, p.37-48, 2019. DOI: http://doi.org/10.6008/CBPC2236-9600.2019.002.0005 


\section{INTRODUÇÃO}

Intoxicação é uma manifestação clínica, resultado dos efeitos tóxicos, a partir de qualquer substância tóxica que possa lesar o corpo através da ação química de forma inalada, ingerida, absorvida, aplicada à pele ou até mesmo produzida no corpo em pequena quantidade (FORTES, 2016). A ciência que estuda e analisa as intoxicações é a toxicologia, que segundo Oga et al. (2014), estuda os efeitos que as substâncias químicas produzem nos sistemas biológicos, dividida em: clínica, que promove o atendimento àquele intoxicado; analítica, que estuda e identifica o agente químico referente à exposição do toxicante; e a experimental, que desenvolve estudos para elucidar a ação dos agente tóxicos no sistema biológico e avaliar os efeitos dessa ação.

As intoxicações podem ser do tipo exógena e endógena. A exógena, de acordo com Dantas (2013) é definida como a consequência por exposição a substâncias químicas do ambiente ou isoladas, como plantas, pesticidas, medicamentos, produtos químicos, entre outros. Segundo Amorim (2018), a intoxicação exógena é causada devido à exposição inadequada do indivíduo a agentes tóxicos, e representa uma emergência médica, bem como um caso de grande preocupação para a saúde pública, merecendo grande atenção à mesma, visto que, se manifesta com dados clínicos evidentes de risco de vida, causados de forma acidental ou intencional, onde esta última é bastante emergente por se tratar muitas vezes de tentativa de suicídio.

No que se refere à violência autoinflingida, Veloso (2017) afirma que os pesticidas e os medicamentos juntos, representam cerca de 70\% das intoxicações exógenas. De acordo com Coruja (2012), mesmo não sendo como ato de suicídio, os medicamentos representam altos índices de intoxicação exógena, e isso se dá, principalmente, devido à automedicação, visto que há o risco de administração incorreta dos medicamentos e a falta de conhecimento referente aos mesmos, constituindo, portanto, um grave problema de saúde pública.

Segundo Amorim (2018), dentre as principais causas por intoxicação exógena, há destaque na tentativa de suicídio, o abuso de drogas e/ou álcool e os casos acidentais, sendo configurada como uma urgência/emergência médica, exigindo intervenções precisas e eficazes a curto e médio prazo, bem como ações preventivas para populações de maior vulnerabilidade.

Diante da importância das intoxicações exógenas, e por representarem um meio de tentativa de suicídio e um agravo à saúde pública, a Secretaria Municipal da Saúde de São Paulo afirma que, a mesma está inserida na lista de doenças de agravos de notificação compulsória da Portaria GM/MS no 104 de 25 de janeiro de 2011, e, posteriormente, mantida pela Portaria GM/MS no 1271 de 06 de junho de 2014 e definida sua periocidade de notificação como semanal pelos profissionais de saúde.

Segundo Fortes (2016) a partir das notificações, há uma divulgação de todos os casos nacionais de intoxicações exógenas, a partir do Sistema Nacional de Informações Tóxico-Farmacológicas (SINITOX). Diante do exposto, busca-se uma investigação de casos de intoxicação exógena na cidade de Porto Nacional (TO), para os últimos cinco anos notificados pelo Sistema de Informação de Agravos de Notificação-SINAN, a partir 
do portal DATASUS, que registra todas as notificações patológicas de todos os estados brasileiros, bem como as cidades de notificação.

A investigação de incidência das intoxicações exógenas para o município em questão se dá devido ser um caso de saúde pública, agravado principalmente pelas tentativas de suicídio e automedicação, e, portanto, merece investigação para o município de Porto Nacional (TO), como forma de exposição dos casos para busca de alternativas que visem minimizar esses agravos com ações preventivas, visto que, a partir de buscas, não há artigos que enfatizem essa problemática no município.

\section{METODOLOGIA}

\section{Delineamento do estudo}

Este trabalho é caracterizado como de natureza descritiva, com abordagem quantitativa, através da pesquisa documental. A pesquisa descritiva visa observar, registrar, analisar e ordenar dados de um determinado fenômeno ou população, ou estabelecer as relações entre as variáveis pesquisadas, e caracterizada pela forma de levantamento (PRODANOV et al., 2013).

A pesquisa de abordagem quantitativa, segundo Gerhardt et al. (2009), é aquela que busca resultados quantificados, com representação numérica. Prodanov et al. (2013) afirma que, na pesquisa quantitativa há a tradução dos resultados através de números, para que possam ser classificados e analisados, com o uso de recursos estatísticos, como porcentagem e média. Já relativo à pesquisa documental, Gil (2008) argumenta que é desenvolvida por meio de material já existente, como relatórios e tabelas estatísticas, reelaborados de acordo com os objetivos propostos pela pesquisa.

\section{Local e população do estudo}

Segundo o Instituto Brasileiro de Geografia e Estatística - IBGE (2018), a cidade de Porto Nacional possui uma estimativa de 52.700 pessoas para o ano de 2018, sendo que, no último censo realizado em 2010, a população era de 49.146 pessoas. O local de estudo é a cidade de Porto Nacional, localizada no centro do Estado do Tocantins, a 64 quilômetros da capital do estado, Palmas, conforme a figura 1.

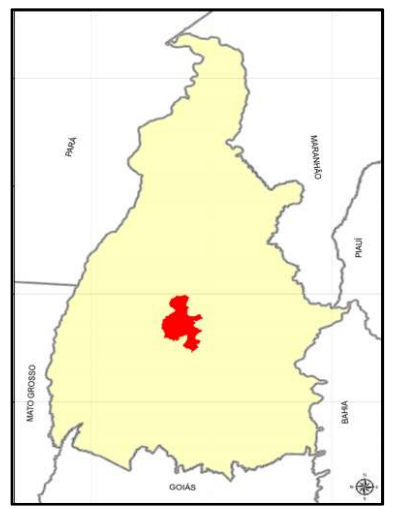

Figura 1: Localização geográfica de Porto Nacional no Estado do Tocantins.

A população de estudo se refere aos habitantes da cidade de Porto Nacional que foram identificados com intoxicação exógena no período de 2013 a 2017, bem como, os habitantes de outros municípios que 
foram identificados e atendidos em Porto Nacional, visto que as unidades de saúde do município atendem pessoas dos municípios vizinhos. Entretanto, não há essa diferenciação, pois, os dados disponíveis sobre a intoxicação exógena são referentes aos casos identificados no município de Porto Nacional.

\section{Coleta de dados}

Os dados foram coletados exclusivamente pelo meio virtual, através de contribuições do Governo Federal, por meio do portal DATASUS do Sistema de Informação de Agravos de Notificação-SINAN, nos meses de março e abril de 2019. Não houve necessidade da anuência de algum órgão para a obtenção desses dados, visto que, eles são disponibilizados a toda a população.

Através do SINAM, coletou-se os dados referentes à incidência da intoxicação exógena na cidade de Porto Nacional (TO) no período de 2013 a 2017, bem como os mesmos dados para o estado do Tocantins, de modo que possa comparar os valores do município com os valores do estado. Segundo Cerqueira Neto (2017), o SINAM é o sistema oficial do governo para a coleta, transmissão, disseminação e exposição dos dados referentes aos agravos das doenças de notificação compulsória instituídas por lei, em âmbito nacional.

Além disso, os conceitos expostos e parâmetros de base que contribuíram para a pesquisa foram obtidos através de livros e artigos científicos. Para a realização da pesquisa, coletou-se as variáveis referentes à: sexo, faixa etária, raça, escolaridade, agente tóxico, circunstância e evolução. Todas as variáveis disponíveis no DATASUS do SINAN.

\section{Análise de dados}

Após a coleta de dados, eles foram agrupados nos programas Excel e Word, do pacote Microsoft Office 365 , para que pudessem ser qualificados, preparados e analisados. Através do programa, todos os gráficos e tabelas foram feitos, bem como, as porcentagens e médias, e analisados estatisticamente para uma melhor exposição dos resultados. Além disso, utilizou-se o teste Qui-Quadrado, no programa Excel, para analisar quais das variáveis possuem evidências de associação quanto à incidência durante o período pesquisado. Para o teste Qui-Quadrado, adotou-se um nível de significância de 5\% ou 0,05 para comparar.

Através do valor de Qui-Quadrado encontrado por meio das fórmulas aplicadas no Excel, utilizou-se as seguintes hipóteses: Se o valor de qui-quadrado encontrado for menor ou igual a 0,05, então a variável possui evidência de associação com a incidência da Intoxicação Exógena pelo período pesquisado em Porto Nacional (TO); Se o valor de qui-quadrado encontrado for superior a 0,05 , então a variável não possui evidência de associação com a incidência da Intoxicação Exógena pelo período pesquisado em Porto Nacional (TO).

Os dados municipais, por serem os principais para a pesquisa, foram comparados aos dados a nível estadual, através dos gráficos e tabelas, para que os resultados tenham uma amplitude maior. A necessidade de comparação dos dados da cidade de Porto Nacional com os dados do estado do Tocantins é significativa, devido à possível verificação se o município acompanha os dados do estado, ou se está menos ou mais evoluído que o mesmo no que se refere à saúde pública. Além disso, é de suma importância visto que a 
intoxicação exógena é um modo utilizado para suicídio, e a comparação realizada é capaz de demostrar a situação do município e expor o risco para tal.

\section{RESULTADOS}

No período de 2013 a 2017, 444 casos de intoxicação exógena foram notificados em Porto Nacional (TO). Sendo que estes foram identificados por ano em quantidades similares, sem seguir um modelo crescente ou decrescente, conforme a figura 2. Para o Estado do Tocantins, o valor é de 6.501 casos, divididos em: 1195 em 2013, 1249 em 2014, 1206 em 2015, 1333 em 2016, e 1518 em 2017. A maior incidência foi para o ano de 2017, sendo que de 2015 a 2016 a incidência foi crescente. Dentre todos os casos notificados por ano de 2013 a 2017, há uma divisão entre notificação por sexo, conforme a figura 3.

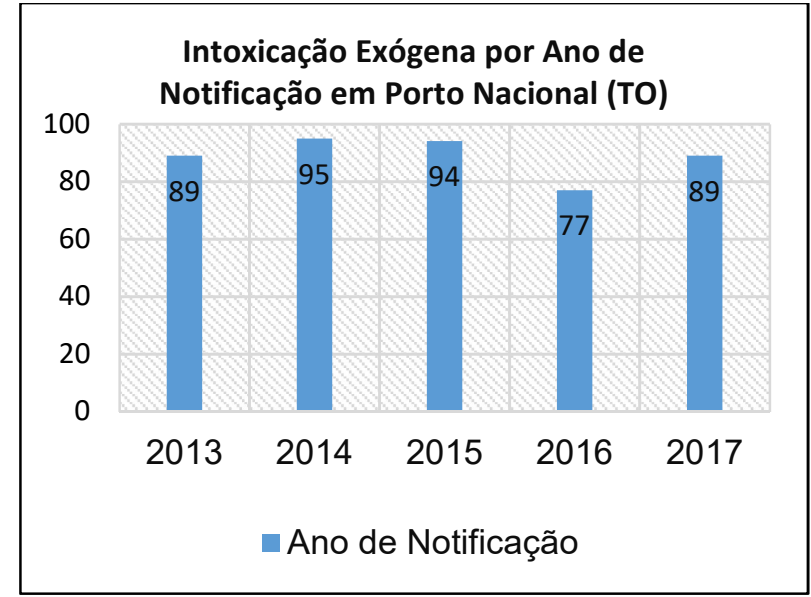

Figura 2: Ano de Notificação da Intoxicação Exógena em Porto Nacional (TO).

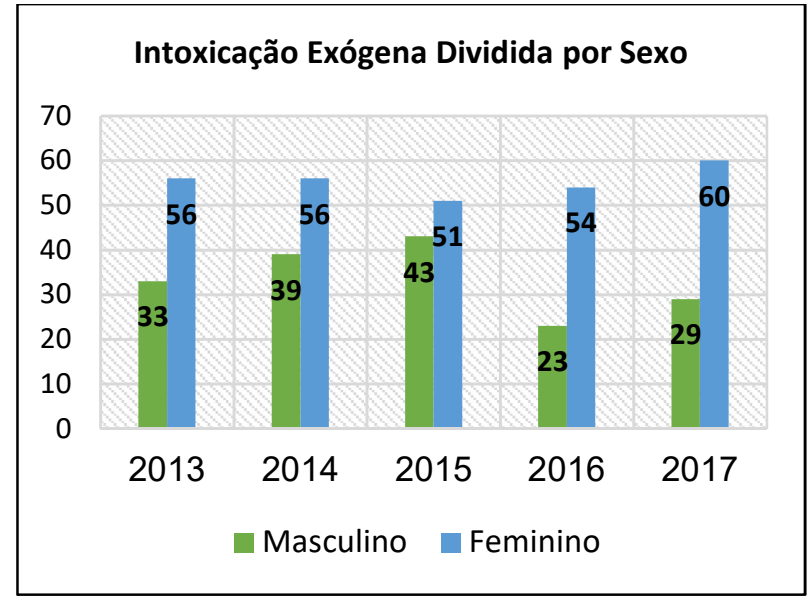

Figura 3: Sexo de notificação da intoxicação exógena.

Percebe-se que em todos os anos a intoxicação exógena foi maior para o sexo feminino, onde em 2013 representa cerca de 62,92\% do total, em 2014 representa em torno de 58,95\% do total, em 2015 o sexo feminino representa 54,25\%, em 2016 esse valor sobe para cerca de 70,13\% e em 2017 o valor refere-se a 67,42\%. Para todo o período, houve um total de 277 casos de mulheres vítima de intoxicação exógena, representando $62,39 \%$ do total de 444 casos. Os dados do Estado do Tocantins possuem a mesma linha de notificação, onde, para todo o período pesquisado, houve 2 casos que o sexo foi ignorado, 3581 casos de intoxicação no sexo feminino, representando $55,08 \%$ do total de casos, e 2893 casos de intoxicação no sexo masculino ou $44,5 \%$ do total.

Ao submeter os dados referentes a incidência por sexo para todo o período pesquisado no teste QuiQuadrado, foi encontrado um valor de 0,19, sendo superior ao nível de significância de 0,05 adotado. Portanto, o sexo não possui evidência de associação com a intoxicação exógena. Apesar de haver mais notificações para o sexo feminino, este não é um fator determinante na incidência do município de Porto Nacional (TO) durante o período pesquisado.

Para a notificação dividida por raça, foi identificado que em todos os anos a intoxicação exógena foi maior na raça/cor parda, totalizando 401 casos com essa raça/cor para todo o período, o que representa 
$90,31 \%$ do total. Houve poucas notificações para as raças branca, preta e amarela, e em alguns casos a raça foi ignorada, conforme a figura 4.

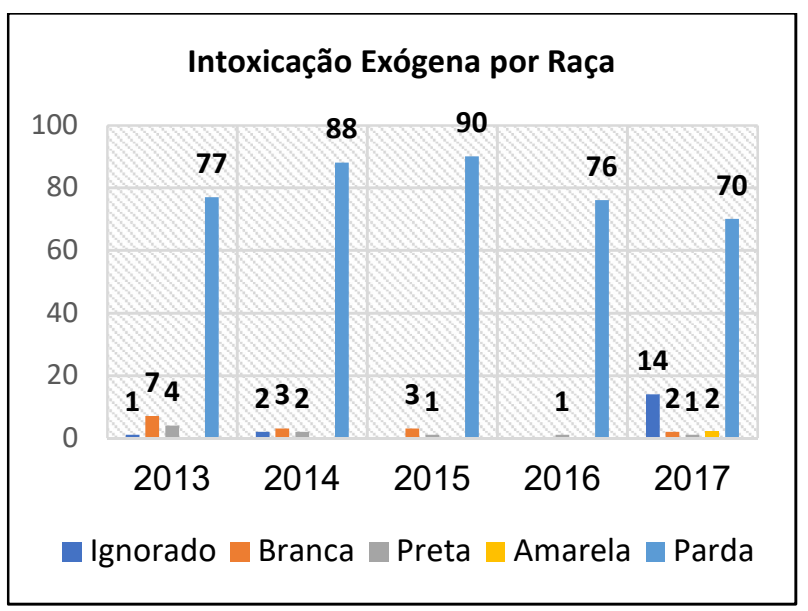

Figura 4: Notificação de intoxicação exógena por raça em Porto Nacional (TO).

A incidência por raça também foi muito maior para a parda no Estado do Tocantins, onde, para todo o período pesquisado houve 5221 casos ou $80,31 \%$ do total. Através do teste Qui-Quadrado, encontrou-se

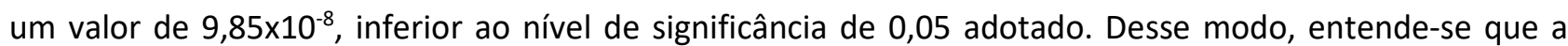
raça/cor possui evidência de associação com a intoxicação exógena em Porto Nacional (TO).

No que se refere à faixa etária dos pacientes atendidos e notificados com intoxicação exógena em Porto Nacional (TO), há poucas notificações para a faixa etária menor de 1 ano, e poucas acima de 60 anos, em nenhum ano essas faixas etárias foram significativas. Considerando todo o período, houve 151 casos com a faixa etária de 20 a 39 anos, 116 de 1 a 4 anos e 62 de 15 a 19 anos, também houve notificações para outras faixas etárias, porém não muito grandes, conforme a tabela 1.

Tabela 1: Intoxicação exógena por faixa etária em Porto Nacional - TO, de 2013 a 2017.

\begin{tabular}{|c|c|c|c|c|c|c|c|}
\hline FAIXA ETÁRIA/ANO & 2013 & 2014 & 2015 & 2016 & 2017 & TOTAL & $\%$ \\
\hline Menos de 1 ano & 4 & 0 & 6 & 3 & 1 & 14 & $3,15 \%$ \\
\hline 1 a 4 anos & 16 & 34 & 30 & 17 & 19 & 116 & $26,13 \%$ \\
\hline 5 a 9 anos & 3 & 9 & 1 & 10 & 4 & 27 & $6,08 \%$ \\
\hline 10 a 14 anos & 4 & 3 & 2 & 4 & 7 & 20 & $4,5 \%$ \\
\hline 15 a 19 anos & 12 & 8 & 10 & 10 & 22 & 62 & $13,96 \%$ \\
\hline 20 a 39 anos & 35 & 28 & 31 & 26 & 31 & 151 & $34,01 \%$ \\
\hline 40 a 59 anos & 12 & 12 & 10 & 5 & 4 & 43 & $9,68 \%$ \\
\hline 60 anos ou mais & 3 & 1 & 4 & 2 & 1 & 11 & $2,48 \%$ \\
\hline
\end{tabular}

O município segue os números do Estado do Tocantins, que em todo período pesquisado, a faixa etária com maior notificação também foi a de 20 a 39 anos, com 2.317 casos ou 35,64\% do total de 6501 casos, e em segundo lugar também destaca-se a faixa etária de 1 a 4 anos, com 1.408 casos ou 21,66\% do total. Para o teste Qui-Quadrado, foi encontrado um valor de 0,0028, menor que o nível de significância de 0,05 adotado. Entende-se, portanto, que a faixa etária é uma variável associada à incidência de intoxicação exógena no município de Porto Nacional (TO).

No que se refere à escolaridade dos pacientes notificados com intoxicação exógena de 2013 a 2017 em Porto Nacional (TO), ela é bastante heterogênea para todos os anos, em nenhum houve uma escolaridade muito prevalente. Em todos os anos, a maior notificação da escolaridade é a opção 'não se aplica', isso porque 
há uma grande incidência de intoxicação exógena em crianças fora da idade escolar, e a segunda opção fica com o fundamental incompleto, exceto para o ano de 2017 que a segunda maior opção é o ensino médio completo. Considerando todo o período pesquisado, a maior notificação não teve a escolaridade aplicada, e a segunda maior opção é de fundamental incompleto com 15,79\% do total, conforme a tabela 2.

Tabela 2: Intoxicação exógena por escolaridade em Porto Nacional - TO, de 2013 a 2017.

\begin{tabular}{|c|c|c|c|c|c|c|c|}
\hline ESCOLARIDADE/ANO & 2013 & 2014 & 2015 & 2016 & 2017 & TOTAL & $\%$ \\
\hline Ignorado/Em branco & 2 & 6 & 11 & 7 & 20 & 46 & $10,36 \%$ \\
\hline Analfabeto & 2 & 0 & 5 & 2 & 1 & 10 & $2,25 \%$ \\
\hline Fundamental incompleto & 34 & 15 & 14 & 16 & 11 & 90 & $20,27 \%$ \\
\hline Fundamental Completo & 1 & 4 & 2 & 1 & 3 & 11 & $2,48 \%$ \\
\hline Ensino Médio Incompleto & 13 & 10 & 9 & 9 & 18 & 59 & $13,29 \%$ \\
\hline Ensino Médio Completo & 8 & 13 & 11 & 9 & 8 & 49 & $11,04 \%$ \\
\hline Ensino Superior Incompleto & 4 & 3 & 3 & 5 & 3 & 18 & $4,05 \%$ \\
\hline Ensino Superior Completo & 4 & 2 & 2 & 3 & 1 & 12 & $2,7 \%$ \\
\hline Não se aplica & 21 & 42 & 37 & 25 & 24 & 149 & $33,56 \%$ \\
\hline
\end{tabular}

Para o Estado do Tocantins, a incidência por escolaridade também possui o mesmo perfil. Houve 1801 casos onde a escolaridade não foi aplicada, e em segundo lugar, assim como no município, destaca-se o fundamental incompleto com 1271 casos ou 19,55\% do total. Através do teste Qui-Quadrado para esta variável de escolaridade, identificou-se um valor de 0,00029, inferior ao valor de significância de 0,05 adotado, portanto esta é uma variável com evidência de associação à incidência no município.

Ao analisar os agentes tóxicos causadores da intoxicação exógena, é observado que dentre as opções há: medicamentos, agrotóxicos agrícolas, agrotóxicos domiciliares, raticidas, produtos veterinários, produtos de uso domiciliar, produtos químicos, cosméticos, plantas tóxicas, alimentos, ou outro agente não especificado. Em todo o período pesquisado, de 2013 a 2017, os medicamentos são os principais agentes da intoxicação exógena em Porto Nacional (TO), apesar de haver 12 tipos de notificações em agentes, somente os medicamentos representaram $44,59 \%$ do total. Além disso também houve muitas notificações por produtos de uso domiciliar e raticidas, conforme a tabela 3 .

Tabela 3: Notificações de Intoxicação exógena por agentes tóxicos em Porto Nacional (TO), de 2013 a 2017.

\begin{tabular}{|c|c|c|c|c|c|c|c|}
\hline AGENTES TÓXICOS/ANO & 2013 & 2014 & 2015 & 2016 & 2017 & TOTAL & $\%$ \\
\hline Ignorado/Em branco & 5 & 3 & 3 & 7 & 3 & 21 & $4,73 \%$ \\
\hline Medicamento & 45 & 42 & 26 & 32 & 53 & 198 & $44,59 \%$ \\
\hline Agrotóxico Agrícola & 6 & 9 & 9 & 2 & 0 & 26 & $5,85 \%$ \\
\hline Agrotóxico Doméstico & 3 & 4 & 5 & 2 & 6 & 20 & $4,5 \%$ \\
\hline Raticida & 7 & 10 & 17 & 3 & 7 & 44 & $9,9 \%$ \\
\hline Produto Veterinário & 0 & 3 & 5 & 1 & 0 & 9 & $2,03 \%$ \\
\hline Produto de Uso Domiciliar & 9 & 9 & 15 & 12 & 12 & 57 & $12,84 \%$ \\
\hline Produto Químico & 9 & 6 & 5 & 3 & 4 & 27 & $6,08 \%$ \\
\hline Cosmético & 1 & 0 & 1 & 2 & 0 & 4 & $0,9 \%$ \\
\hline Planta tóxica & 2 & 3 & 4 & 8 & 1 & 18 & $4,05 \%$ \\
\hline Alimento e Bebida & 0 & 1 & 0 & 0 & 1 & 2 & $0,45 \%$ \\
\hline Outro & 2 & 5 & 4 & 5 & 2 & 18 & $4,05 \%$ \\
\hline
\end{tabular}

A intoxicação por medicamentos representa um número preocupante, visto que tem se mantido em alta em todos os anos. Ressalta-se a diferença do número de notificações por medicamentos e por produtos de uso domiciliar que ocupa a segunda posição, enquanto o primeiro possui quase $45 \%$, o segundo não chega a 13\%, uma diferença bastante alta que evidencia a preocupação da intoxicação medicamentosa. 
Para o Estado do Tocantins, o perfil por agentes tóxicos é semelhante, visto que, assim como no município, os medicamentos foram os principais agentes da intoxicação exógena, com 2.199 casos no estado ou 33,82\% do total. Porém, diferente do município, a segunda posição de intoxicação exógena é por alimento ou bebida, com 731 casos, ou 11,24\% do total. Através do teste Qui-Quadrado, foi encontrado um valor de 0,0026, menor que o valor de 0,05 de significância adotado. Desse modo, percebe-se que os agentes tóxicos possuem evidência de associação com a incidência da intoxicação exógena em Porto Nacional (TO) durante o período pesquisado.

As circunstâncias que levaram as vítimas a contrair intoxicação exógena notificadas em Porto Nacional (TO) são referentes a: uso habitual do agente tóxico, acidental, ambiental, uso terapêutico, erro de administração do agente, automedicação, ingestão de alimento, tentativa de suicídio, tentativa de aborto, violência/homicídio, e outras não especificadas. Em todo o período pesquisado, a tentativa de suicídio foi a circunstância mais frequente, apesar de haver outros 11 tipos de circunstância, ela representou mais de $50 \%$ do total de 444 casos. Já a segunda posição se refere aos acidentes, com 39,19\% dos casos, enquanto as outras circunstâncias não tiveram valores tão significativos, como se pode observar na tabela 4.

Tabela 4: Notificações de Intoxicação exógena por circunstâncias em Porto Nacional - TO, de 2013 a 2017.

\begin{tabular}{|c|c|c|c|c|c|c|c|}
\hline CIRCUNSTÂNCIAS/ANO & 2013 & 2014 & 2015 & 2016 & 2017 & TOTAL & $\%$ \\
\hline Ignorado/Em branco & 2 & 1 & 0 & 3 & 3 & 9 & $2,03 \%$ \\
\hline Uso habitual & 4 & 1 & 1 & 0 & 0 & 6 & $1,35 \%$ \\
\hline Acidental & 28 & 48 & 40 & 31 & 27 & 174 & $39,19 \%$ \\
\hline Ambiental & 0 & 2 & 0 & 0 & 0 & 2 & $0,45 \%$ \\
\hline Uso terapêutico & 0 & 0 & 2 & 0 & 1 & 3 & $0,67 \%$ \\
\hline Erro de administração & 0 & 0 & 1 & 1 & 1 & 3 & $0,67 \%$ \\
\hline Automedicação & 0 & 3 & 1 & 2 & 2 & 8 & $1,8 \%$ \\
\hline Ingestão de Alimentos & 0 & 2 & 0 & 0 & 0 & 2 & $0,45 \%$ \\
\hline Tentativa de suicídio & 53 & 36 & 47 & 38 & 55 & 229 & $51,58 \%$ \\
\hline Tentativa de aborto & 1 & 2 & 1 & 1 & 0 & 5 & $1,12 \%$ \\
\hline Violência/homicídio & 1 & 0 & 0 & 1 & 0 & 2 & $0,45 \%$ \\
\hline Outro & 0 & 0 & 1 & 0 & 0 & 1 & $0,22 \%$ \\
\hline
\end{tabular}

Para o Estado do Tocantins, o perfil por circunstâncias é diferente. Houve uma maior prevalência para o modo acidental, com 2406 casos ou 37,01\% do total, enquanto a tentativa de suicídio ficou em segundo lugar, com 1968 casos, ou 30,27\% do total. Submetidos os dados das circunstâncias no teste QuiQuadrado, encontrou-se um valor de 0,05, que se iguala ao valor de significância adotado. Desse modo, entende-se que as circunstâncias possuem estão diretamente relacionadas à incidência da intoxicação exógena no município de Porto Nacional (TO) para o período pesquisado.

Para o Estado do Tocantins, a evolução da intoxicação exógena possui o mesmo perfil do município de Porto Nacional (TO), devido à maior parte dos casos serem de cura sem sequela, com 5673 casos ou $87,26 \%$ do total. Entretanto, diferente do município, o estado notificou 32 casos de óbito por intoxicação exógena, mas há pouca representatividade, visto que, se refere à menos de 1\% do total.

A evolução dos casos de intoxicação exógena notificados em Porto Nacional (TO) é classificada em: cura sem sequela, cura com sequela, óbito por intoxicação exógena, óbito por outra casa, perda de seguimento. Não houve nenhum caso de óbito, e a maioria das vítimas tiveram cura sem sequela, conforme a figura 5 . 


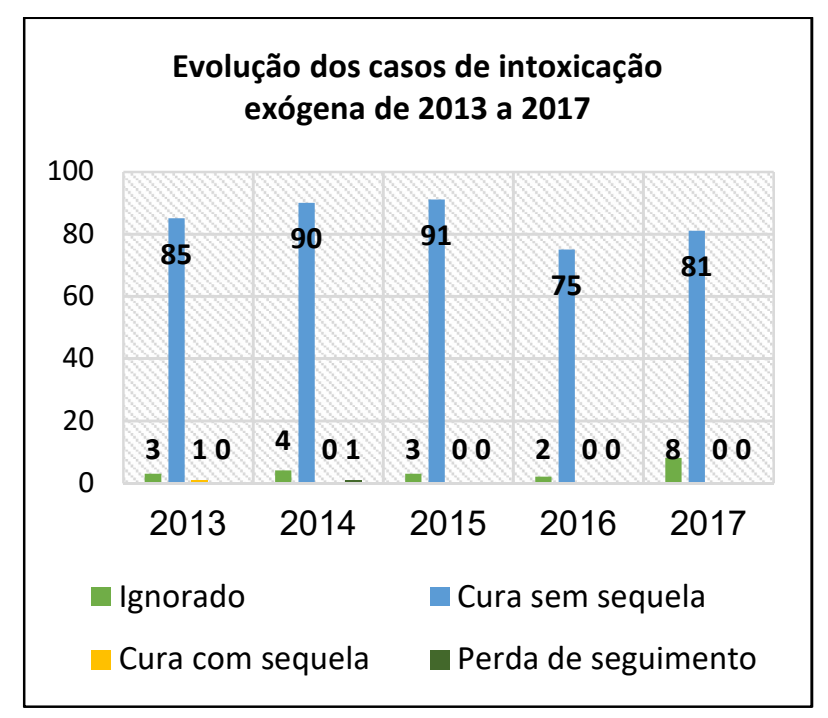

Figura 5: Evolução dos casos de intoxicação exógena em Porto Nacional (TO) de 2013 a 2017.

\section{DISCUSSÃO}

Em um período de 5 anos, houve um alto número de notificações por intoxicação exógena, totalizando 444 casos. Destes, 89 são de 2013, 95 de 2014, 94 de 2015, 77 de 2016 e 89 de 2017. Os casos não seguiram uma linha ao longo dos anos, aumentaram e diminuíram sem um padrão. O menor número registrado foi em 2016, e o maior em 2014. Entretanto não uma evolução, apesar de em 2016 ter registrado o menor número, em 2017 as notificações voltaram a crescer.

Vale ressaltar que o município atende a população do seu entorno também, como os pacientes das cidades de Monte do Carmo, Brejinho de Nazaré, Silvanópolis, entre outras, devido elas não possuírem hospitais regionais. As notificações do município por ano se diferem dos números do Estado do Tocantins, que teve a menor notificação em 2013, e de 2015 a 2017 houve um aumento na incidência da intoxicação exógena. Do total de 6.501 casos registrados no estado, o município de Porto Nacional representa 6,83\%.

Em todos os anos, as mulheres foram as maiores vítimas de intoxicação exógena no município, com mais de 50\% dos casos, e em 2016 esse número chegou a mais de 70\% dos casos. Ao comparar por todo o período, há um total de 277 mulheres, o que representa $62,39 \%$ do total, um valor bem superior ao total de vítimas do sexo masculino. Essas notificações do município se assemelham às notificações do Estado, que durante o mesmo período as mulheres também foram as principais vítimas, com 55,08\% do total de casos. Apesar disso, identificou-se por meio do teste Qui-Quadrado que esta não é uma variável com evidência de associação com os casos de intoxicação exógena no município.

No que se refere à raça, em todo o período pesquisado, a maioria das vítimas foi identificada como da raça parda. Cerca de 86,52\% em 2013, 92,63\% em 2014, 95,74\% em 2015, 98,7\% em 2016 e 78,65\% em 2017. A média para todo o período pesquisa é de $90,32 \%$ de pardos para o total de 444 casos. Compara-se ao estado do Tocantins, onde há a incidência de $80,31 \%$ para a raça/cor parda, pouco menor que no município de Porto Nacional. Além disso, esta é uma variável que possui evidência de associação com a incidência da intoxicação exógena no município, identificada por meio do teste Qui-quadrado. 
Foi observado que a faixa etária que mais prevalece para os casos de intoxicação exógena de 2013 a 2017 é de 20 a 39 anos, com 151 casos, representando cerca de 34\% do total, além desta ser uma variável associada às notificações, identificado por meio do teste Qui-Quadrado. Cabe ressaltar que as faixas etárias de 1 a 4 anos e 15 a 19 anos também tiveram muitas notificações, onde a de 1 a 4 anos teve 116 casos, representando em torno de $26,13 \%$ do total, e a faixa de 15 a 19 anos com 62 casos ou 13,96\% do total. As outras faixas etárias não tiveram muita relevância. As faixas mais prevalentes do município comparam-se às faixas do estado, onde de 20 a 39 anos a incidência foi de $35,64 \%$ do total, pouco maior que em Porto Nacional, e de 1 a 4 anos foi de 21,66\% do total, pouco menor que no município pesquisado.

No que se refere à escolaridade, em todos os anos a maioria dos casos a mesma não foi aplicada, e em segunda opção prevalece o ensino fundamental incompleto, com cerca de $20,27 \%$ do total de 444 casos. O que evidencia a falta de conhecimento das vítimas de intoxicação exógena, sendo, portanto, uma parcela de população desfavorecida, além disso, essa variável, de acordo com o teste Qui-Quadrado, está diretamente associada à incidência de intoxicação exógena. O mesmo ocorre no Estado do Tocantins, onde a escolaridade de maior prevalência também foi a de fundamental incompleto, com 19,55\% do total, valor bem próximo ao do município de Porto Nacional (TO).

Ao analisar os agentes tóxicos, é perceptível que medicamentos aparecem em todos os anos como os principais causadores da intoxicação exógena, bem superiores aos outros agentes. Para todo o período, o total de intoxicação por medicamentos é de 198 casos, o que representa quase $45 \%$ do total de 444 casos, mesmo havendo outros 11 tipos de agentes notificados, um valor muito significativo que abre espaço futuras investigações quanto à intoxicação medicamentosa no município. Esta variável de agentes tóxicos é um fator determinante para a incidência da intoxicação exógena no município, visto que, a partir do teste QuiQuadrado, identificou-se que possui associação com os casos.

Além disso, de 2015 a 2017, a intoxicação por medicamentos teve um crescimento considerável, o que leva a uma preocupação quanto ao avanço da medicina, aliado ao acesso das pessoas aos fármacos. Os outros agentes tóxicos não tiveram uma incidência tão alta, entretanto ressalta-se que os produtos de uso domiciliar e os raticidas também são preocupantes. Esses três principais agentes são encontrados nos lares, algo que justifica a alta incidência de intoxicação na faixa etária de 1 a 4 anos, por se tratar de crianças sem conhecimento quanto ao perigo do que brincam.

A incidência por agentes tóxicos no Tocantins também apresentou os medicamentos como a principal causa, com 33,82\% do total. Já a segunda posição se difere do município, por apresentar 11,24\% de casos de intoxicação por alimento ou bebida. Quanto às circunstâncias que levaram à intoxicação exógena, a principal foi a tentativa de suicídio, com 229 casos ou 51,58\% do total. É um valor muito preocupante e que segue os dados nacionais, visto que, segundo Santos et al., (2014), a intoxicação exógena é uma das três principais causas da tentativa de suicídio no país.

Outra circunstância significativa foi a acidental, com 174 casos ou $39,19 \%$ do total. Ao comparar esse valor com a faixa etária, ele é explicado devido à alta incidência para a faixa etária de 1 a 4 anos que teve $26,13 \%$ do total. Para essa faixa etária, o meio acidental é o mais comum, visto que, crianças não possuem 
entendimento para classificar os riscos. Além disso, identificou-se que as circunstâncias estão associadas à incidência de intoxicação exógena no município, por meio do teste Qui-Quadrado.

O município de Porto Nacional (TO) não segue o perfil de circunstâncias do Estado, pois este apresenta o modo acidental como a principal, com pouco mais de $37 \%$ dos casos, e a tentativa de suicídio em segundo lugar, com pouco mais de $30 \%$, enquanto no município é o inverso, onde a tentativa de suicídio possui o maior destaque, ultrapassando mais da metade das notificações. Esse é um fator preocupante do município de Porto Nacional (TO), pois evidencia os problemas psicológicos, sociais e até mesmo depressivos que levam à tentativa de suicídio. Apesar de esse fator também ser preocupante no estado, em Porto Nacional é ainda maior. Devendo ser analisado pelos poderes responsáveis vigentes, de modo a prevenirem essas tentativas e diminuir a incidência de intoxicação exógena por esta circunstância.

Já a evolução dos casos no município, cerca de 95,05\% dos casos obtiveram cura sem sequela. Houve somente um caso de cura com sequela. Isso evidencia o bom funcionamento da saúde pública, pois não há hospitais particulares, do município para o tratamento de intoxicação exógena. Além disso, não houve nenhuma notificação de óbito por intoxicação exógena, um dado bastante considerável. Os dados se assemelham à evolução dos casos do estado, bem como ao bom funcionamento da saúde pública para o tratamento, onde houve $87,26 \%$ de casos com cura sem sequela.

\section{CONCLUSÕES}

A partir do teste Qui-Quadrado, identificou-se que as variáveis que possuem evidência de associação com as notificações de intoxicação exógena em Porto Nacional (TO) durante o período pesquisado são: raça/cor, faixa etária, escolaridade, agentes tóxicos e circunstâncias. Estes são fatores preocupantes que evidenciam que a raça parda está relacionada à incidência, especialmente porque esta possui uma prevalência muito alta. Há também uma preocupação quanto a faixa etária, visto que as maiores notificações se referem a pessoas entre 20 e 39 anos e crianças, e por estar associada à incidência, preocupa-se ao aliar com as circunstâncias, que as maiores são relacionadas à tentativa de suicídio e à forma acidental.

A associação da escolaridade com a incidência também é um fator preocupante, pois a grande maioria das notificações de intoxicação exógena se refere a pessoas de baixa escolaridade, desse modo, pode-se analisar que a maior parcela de notificações se dá a partir de pessoas com pouco conhecimento, principalmente quanto a intoxicação exógena. Os agentes tóxicos, por estarem diretamente associados à incidência, também são fatores preocupantes, especialmente devido à alta incidência de intoxicação medicamentosa, muito superior aos outros agentes.

No que se refere ao perfil epidemiológico, é possível concluir que, de modo geral, este é caracterizado pela predominância em vítimas do sexo feminino, raça/cor parda, faixa etária de 20 a 39 anos, com baixa escolaridade (fundamental incompleto), através do uso de medicamentos como o causador da intoxicação, especialmente para a tentativa de suicídio, porém contrariando à tentativa, os casos possuem cura sem sequela. 
O perfil é preocupante, visto que, trata-se de mulheres com baixo conhecimento, em idade jovem, e que, na grande maioria dos casos, buscam o suicídio. É necessária uma maior atenção do poder público e da sociedade aos sinais de depressão, pois, segundo Assumpção et al. (2018) esta é a doença de maior influência para os atos suicidas. Para o Estado do Tocantins, o perfil epidemiológico é semelhante, a diferença é a circunstância da intoxicação, que predomina a acidental, enquanto no município é a tentativa de suicídio. 0 conhecimento do perfil epidemiológico das vítimas de intoxicação exógena é fundamental para que haja desenvolvimento de estratégias e ações preventivas (CERQUEIRA NETO, 2017).

\section{REFERÊNCIAS}

AMORIM, V. O.. Atendimentos por intoxicações exógenas no estado de Sergipe. In: CONGRESSO DE URGÊNCIA E EMERGÊNCIA DE SERGIPE, 2. Anais. Aracaju: UNIT, 2018.

ASSUMPÇÃO, G. L. S.; OLIVEIRA, L. A.; SOUZA, M. F. S.. Depressão e suicídio: uma correlação. Revista de Graduação em Psicologia da PUC Minas, v.3, n.5, 2018.

CERQUEIRA NETO, P. T.. Óbitos por intoxicação exógena no município de São Paulo, Brasil. São Paulo: USP, 2017.

CORUJA, C. I. K.. Intoxicação por paracetamol no Rio Grande do Sul. Porto Alegre: UFRGS, 2012.

FORTES, A. F.. Intoxicações exógenas: perfil dos pacientes atendidos em um pronto atendimento. Revista Eletrônica Gestão \& Saúde, v.7, n.1, 2016.

GERHARDT, T. E.; SILVEIRA, D. T.. Métodos de pesquisa. Porto Alegre: UFRGS, 2009.
GIL, A. C.. Métodos e Técnicas de Pesquisa Social. 6 ed. São Paulo: Atlas, 2008.

IBGE. Instituto Brasileiro de Geografia e Estatística. Porto Nacional. Rio de Janeiro: IBGE, 2018.

OGA, S.; SIQUEIRA, M. E. P. B.. Introdução à Toxicologia: Fundamentos de toxicologia. 4 ed. São Paulo: Atheneu, 2014.

PRODANOV, C. C.; FREITAS, E. C.. Metodologia do trabalho científico: métodos e técnicas da pesquisa e do trabalho científico. 2 ed. Novo Hamburgo: Universidade Feevale, 2013.

VELOSO, C.. Violência autoinfligida por intoxicação exógena em um serviço de urgência e emergência. Revista Gaúcha de Enfermagem, v.38, n.2, 2017.

A CBPC - Companhia Brasileira de Produção Científica (CNPJ: 11.221.422/0001-03) detém os direitos materiais desta publicação. Os direitos referem-se à publicação do trabalho em qualquer parte do mundo, incluindo os direitos às renovações, expansões e disseminações da contribuição, bem como outros direitos subsidiários. Todos os trabalhos publicados eletronicamente poderão posteriormente ser publicados em coletâneas impressas sob coordenação da Sustenere Publishing, da Companhia Brasileira de Produção Científica e seus parceiros autorizados. Os (as) autores (as) preservam os direitos autorais, mas não têm permissão para a publicação da contribuição em outro meio, impresso ou digital, em português ou em tradução. 